\title{
Obtaining the ideal smoked bacon: What is the influence of the product space and multivariate procedure to construct the external preference mapping?
}

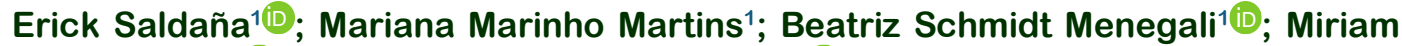 \\ Mabel Selani ${ }^{2}$ (D); Carmen J. Contreras-Castillo ${ }^{1 *}$ (D) \\ 1 Universidade de São Paulo (USP), Escola Superior de Agricultura "Luiz de Queiroz" (ESALQ), Departamento de \\ Agroindústria, Alimentos e Nutrição (LAN), Piracicaba, SP 13418-900, Brazil. \\ 2 Universidade Federal de São Carlos - Campus Lagoa do Sino, Centro de Ciências da Natureza, Buri, SP, Brazil.
}

Received February 11, 2019. Accepted March 17, 2019.

\begin{abstract}
Identifying the ideal product is the most important step in new product development and improvement of existing ones. The aim of this study was to identify the ideal smoked bacon using PrefMFA and PrefMap considering three different sensory spaces obtained via descriptive analysis (DA), projective mapping (PM) and CATA questions. Six smoked bacons were characterized by ten trained assessors using DA, and by two consumers panel using PM $(n=93)$ and CATA questions $(n=100)$. Also, one hundred consumers indicated their overall liking using a nine-point hedonic scale. The results showed that both techniques identified an ideal product. However, the sensory method has a greater effect than the multivariate procedure to obtain the sensory spaces prior to the preference mapping. Subsequent studies with other food matrices are still necessary in order to generalize our results.
\end{abstract}

Keywords: PrefMFA; Sensory profile; Overall liking; Ideal bacon.

\section{Introduction}

The manufacture and consumption of meat products in the Brazilian market has been increasing in recent years. Bacon is one of the most consumed meat products due to its pleasant sensory characteristics, developed during the curing and smoking processes (Saldaña et al., 2018). The sensory properties of bacon are mainly driven by smoking process that provides the smoke flavor, which is highly appreciated by consumers (Kathrine et al., 2013). For this reason, the sensory profile is considered the best intrinsic predictor of consumers' liking (Saldaña et al., 2018). Listening to "the voice of the consumer" is a decisive step in the development or improvement of a product (van Kleef et al., 2005). Therefore, characterizing the product through sensory (sensory attributes) and hedonic (overall liking) perspectives is necessary, because together these data will identify the "drivers of liking" (Cariou et al., 2014) and finally the ideal product (Ares et al., 2011). Classically, the ideal product is obtained using the external preference mapping (PrefMap). The aim of PrefMap is to determine which sensory attributes explain the differences in overall liking (Lê y Worch, 2014) and is constructed in two steps (van Kleef et al., 2006): (a) determining the sensory space of the product via multivariate procedure, and (b) regressing the hedonic rating in this space (Cariou et al., 2014) using polynomial models. External preference mapping was used in a wide variety of products ranging from dulce de leche (Ares et al. ,2006) to plain yogurts (Masson et al.; 2016). In the meat science field, the PrefMap was applied to obtain the sensory attributes that drive the consumers liking of dry-cured ham (Resano et al., 2010). On the other hand, Arditti (1997) applied preference mapping to investigate chicken nuggets using a sensometric

Saldaña, E.; Marinho, M.; Schmidt, B.; Selani, M.M.; Contreras-Castillo, C.J. 2019. Obtaining the ideal smoked bacon: What is the influence of the product space and multivariate procedure to construct the external preference mapping? Scientia Agropecuaria 10(1): 29-37. 
perspective. This study included the selection of dimensions and models involved in the polynomial regression. Oltra et al. (2015) used the preference mapping to identify the quality attributes that drive consumers' preferences for grilled lamb Longissimus lumborum. Despite all the advantages presented by the PrefMap, this technique has some limitations:

a) The first two dimensions of the product space are not always relevant to predict the overall liking of the consumers. However, the use of more dimensions will increase the number of parameters of the model, compromising the number of samples evaluated in a study;

b) The product space considered in the regression to model the liking is provided by trained assessors, and this space is not always relevant for consumer responses (Cariou et al., 2014; Worch, 2013). This fact can lead to irrelevant models for some consumers and therefore to a low predictive power.

In the current study, the last limitation will be addressed. Fitting liking in sensory space is risky, since the sensory space will not represent the ideal product in hedonic terms. To overcome these limitations, Worch (2013) presented a solution taking the best of the internal and external preference mapping techniques: the PrefMFA was born. This new technique of preference mapping uses the Multiple Factor Analysis (MFA) to give the same importance to the sensory and hedonic data in the construction of the perceptual space of the PrefMFA. Nevertheless, few applications of this technique have been reported in the development of foods.

As previously mentioned, the PrefMap is the influence of the product sensory space on the description of the ideal product. For this reason, the following question arises: Is the product sensory space provided by a trained panel the same as that given by the consumers? The answer is no. Consistent with this disadvantage and considering the development of new sensory methods performed by consumers (Ares y Varela, 2017; Valentin et al., 2012), it seems appropriate to use sensory spaces provided directly by consumers. The construction of external preference maps based on consumer sensory space is not a new idea, since Parente et al. (2011) successfully developed external preference maps based on the first two dimensions of the Multiple Factor Analysis performed on the CATA questions data. However, to date, there are no scientific reports that have examined the influence of the sensory space of the product obtained by different consumers sensory methods in the identification and description of the ideal product.

In this context, this study aimed to evaluate the influence of the product space provided by DA, PM, and CATA questions to identify and describe the ideal smoked bacon through the application of PrefMFA and PrefMap.

\section{Materials and methods}

\subsection{Samples}

Six smoked bacon samples were considered in the present study: two were smoked using liquid smoke (LS1 and LS2), three were conventionally smoked using Brazilian woods from reforestation (Bamboo, Eucalyptus and Acacia), and the last one corresponded to a commercial smoked bacon (CS) (Saldaña et al., 2018). Samples manufactured at the University processing plant (LS1, LS2, Bamboo, Eucalyptus and Acacia) were prepared in three independent processing and stored at $-18{ }^{\circ} \mathrm{C}$ until one day before the sensory evaluation, when they were thawed at $4^{\circ} \mathrm{C}$.

To guarantee the chemical characteristics required by the Brazilian legislation, moisture and lipid content of the bacon samples was determined according to the AOAC guidelines (AOAC, 1995). Water activity (Aw) was measured at $25^{\circ} \mathrm{C}$ using a water activity meter (Aqualab 4TE, Decagon Devices, Inc., USA). The $\mathrm{pH}$ was measured using a $\mathrm{pH}$-meter with a puncture electrode inserted into the sample (Saldaña et al., 2015). All measurements were performed in triplicate. Before carrying out the sensory tests, microbiological analyses of the bacon samples were performed to safeguard the integrity of the participants.

\subsection{Sensory space of the products}

The study was carried out by the Sensory Analysis and Consumer Study Group (SACSGroup), which belongs to the Laboratório de Qualidade e Processamento de Carnes of the Departamento de Agroindústria, Alimentos e Nutrição (LAN) of the Escola Superior de Agricultura "Luiz de Queiroz" - Universidade de São Paulo (ESALQ-USP). The Human Research Ethics Committee of the ESALQ-USP (protocol No. 1.550.783) approved this study. All participants read and signed an informed consent form. Samples coded with threedigit random numbers were served to the consumers following a Williams Latin Square design to avoid order presentation bias. Water was used for rinsing between 
samples. The sensory methods were performed according to Figure 1. The sensory space provided by the DA and PM was used as a baseline to select the words used in the CATA questions.

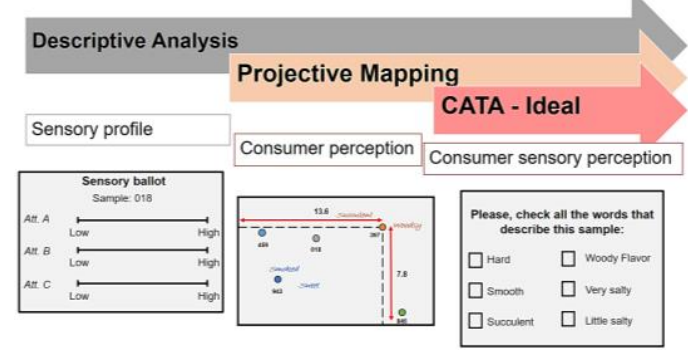

Figure 1. Three sensory methods used to obtain the product sensory space: Descriptive Analysis, Projective Mapping, and CATA questions.

\subsubsection{Descriptive Analysis}

The sensory space of the bacon samples was determined through the DA (Lawless y Heymann, 2010), using ten trained assessors, considering eight sensory attributes (shine, fat content, redness, yellowness, saltiness, fattiness, smokiness and succulence), tasted during three different sessions. Further details of the DA are available in the study of Saldaña et al. (2018).

\subsubsection{Projective Mapping}

The consensus configuration of the samples of the PM method was used as the sensory space of the samples. Ninety-three consumers $(55 \%$ women and $45 \%$ men, aged between 18-62 years) received 6 samples of smoked bacon and evaluated the similarities and differences between them according to their own criteria (Saldaña et al., 2018). Consumers placed the samples on a $A 3$ sheet so that if two samples are similar, they should be close to each other and if they are different, they should be distant to each other (Valentin et al., 2012). When this step was completed, consumers were asked to write a few words close to the product to describe their sensory characteristics, as shown in Figure 1.

\subsubsection{CATA questions and overall liking}

One hundred habitual bacon consumers (40 men and 60 women, aged between 18 - 57 years) tasted monadically 6 bacon samples and answered the CATA questions checking all the terms that they considered appropriate to describe each bacon (Saldaña et al., 2019). The CATA questions were composed of 32 terms related to the sensory profile (Descriptive Analysis) and consumer perception (Projective Mapping) of the bacon samples. To avoid biases due to the long list of terms, the words were presented by category (appearance, odor, texture, and taste). Subsequently, consumers were asked to evaluate their overall liking (OL) using a structured ninepoint hedonic scale, ranging from dislike extremely (1) to like extremely (9).

\subsection{Data analysis}

All data analyses were performed in the $\mathbf{R}$ environment using FactoMineR (Lê et al., 2008) (MFA, CA, and, and RV coefficient), SensoMineR (Lê y Husson, 2008) (PrefMap and PrefMFA) and CVAS (Canonical Variate Analysis) (Peltier, 2015).

\subsubsection{Chemical analysis and overall liking} An analysis of variance (ANOVA) followed by the Tukey's HSD test $(p<0.05)$ on the chemical and liking data were performed. For the chemical data, the one-way ANOVA was considered. For the liking data, the ANOVA model involved sample, consumer, and sample's presentation order as sources of variation. The normality of the residues and homogeneity of the variances were checked before performing the ANOVA test.

\subsubsection{Sensory space of the products}

The DA data were analyzed by CVA based on the Multivariate Analysis of Variance to obtain the sensory space of the products following the guidelines of Peltier et al. (2015). MFA was used to provide the sensory space of the product based on the responses of ninety-three consumers who performed the PM. CATA questions data were analyzed by nonparametric Cochran's $Q$ test on the contingency table to identify the significantly different attributes between bacon samples. Afterwards, correspondence analysis (CA) was performed on the contingency table of the significant terms (Vidal et al., 2015).

\subsubsection{Construction of the preference maps}

The prefMap was carried out according to Macfie (2007) using the coordinates of the sensory space provided by the DA, MP and CATA questions. The prefMFA was analyzed following the recommendations of Worch (2013). The coordinates of the first two dimensions of the prefMFA were based on the MFA, considering sensory (DA, MP and CATA questions) and hedonic (OL) groups as active variables. For both PrefMap and PrefMFA, the OL of each consumer was individually regressed using the first two dimensions (Dim 1 and $\operatorname{Dim}_{2}$ ) using the circular ideal point model (equation 1) (Danzart et al., 2004), since it 
has only 4 parameters (a, b, c, and d). A complete quadratic model is not suitable due to the high number of parameters and the low number of samples.

Liking $=a+\mathrm{b} * \operatorname{Dim}_{1}+\mathrm{c} * \operatorname{Dim}_{2}+\mathrm{d} *\left(\operatorname{Dim}_{1}^{2}+\right.$ $\operatorname{Dim}_{2}^{2}$ )

Where $a$ is the intercept, $b$ and $c$ are the regression coefficients for the first two dimensions, and $d$ is the quadratic parameter. This model was used because the consumers' preferences are not linear (Schlich, 1995), involving four types of consumers: those who express like and dislike, the eclectics, and the nondiscriminators (Danzart et al., 2004). Once the regression model was defined, the overall liking of each consumer was modeled using the first two dimensions of the CVA, MFA, and CA, corresponding for DA, PM and CATA questions, respectively. Subsequently, the $\mathrm{OL}$ areas were discretized in 1 if the estimated liking score was greater than the mean liking provided by the target consumer, and in 0 if the estimated liking was lower than the mean liking (Danzart et al., 2004). Finally, a density plot was created by overlaying all individual consumer's areas. In the plot, areas with maximum density of preference were identified, corresponding to the coordinates of the ideal bacon.

\subsubsection{Comparison of the ideal smoked bacon positioning}

The RV coefficient was used to compare the configuration of the ideal smoked bacon obtained by three sensory product spaces (DA, PM and CATA questions) and two multivariate procedures (prefMap and prefMFA). The RV coefficient indicates the proximity between two configurations resulting from the multivariate analysis (Robert y Escoufier, 1976) and assumes values between 0 (total disagreement) and 1 (total agreement) (El Ghaziri y Qannari, 2015). In addition, each ideal product was characterized by the sensory attributes from each independent method.

\section{Results and discussion}

\subsection{Chemical characteristics of bacon}

All bacon samples manufactured in the processing plant of the University were similar in the chemical characteristics evaluated (Table 1), indicating that pork bellies were homogeneous, and the manufacturing process was similar for all samples. Therefore, it is assumed that changes in the sensory profile are due to the wood or liquid smoke used in the smoking process.
Table 1

Chemical characteristics of the smoked bacon samples

\begin{tabular}{lccc}
\hline Sample & Moisture & $\mathrm{pH}$ & Lipid (\%) \\
\hline Acacia & $44.6 \pm 3.23$ & $5.91 \pm 0.01$ & $38.20 \pm 3.53$ \\
Bamboo & $45.7 \pm 2.48$ & $6.01 \pm 0.11$ & $36.65 \pm 1.30$ \\
Eucalyptus & $46.1 \pm 0.77$ & $5.94 \pm 0.11$ & $37.39 \pm 2.01$ \\
LS1 & $44.6 \pm 2.37$ & $5.88 \pm 0.14$ & $39.98 \pm 1.64$ \\
LS2 & $46.7 \pm 1.13$ & $6.08 \pm 0.06$ & $38.47 \pm 1.30$
\end{tabular}

No significant differences were found between samples by the ANOVA. LS1 and LS2 are samples smoked using two different brands of commercial liquid smoke.

All the chemical characteristics showed values similar to those reported in the literature. The moisture content and $\mathrm{pH}$ values of the samples were similar to those reported by Huang et al. (2014) and the lipid content of the samples were within the range indicated by Soladoye et al. (2017) $(30.71 \%-68.74 \%)$.

\subsection{Sensory analysis of bacon}

Before analyzing the preference maps, it is convenient to present the results of the overall liking, since the products with greater acceptance are expected to be close to the ideal product (if there is an ideal product).

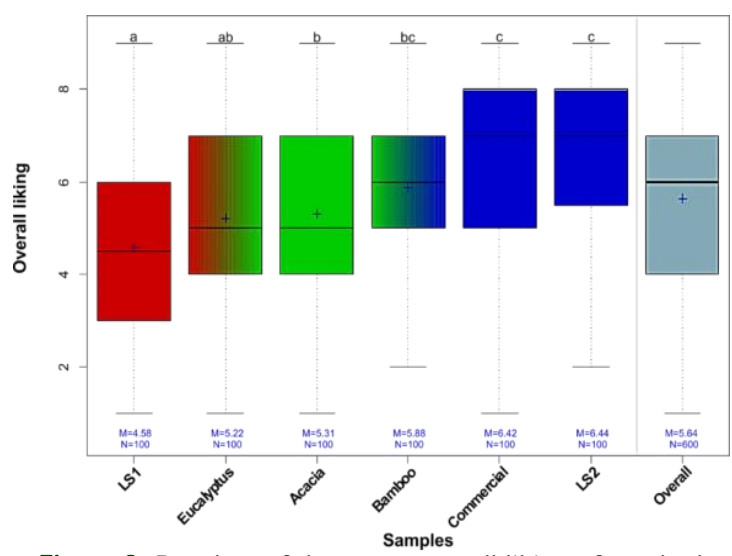

Figure 2. Boxplots of the mean overall liking of smoked bacon samples. Means with the same letter (or with the same color) are not significantly different at $5 \%$ of significance. M: Mean overall liking; $N$ : Number of consumers.

Figure 2 indicates that the commercial and LS2 samples had the highest OL, while LS1 was the least liked. The remaining samples showed an intermediate liking.

\subsubsection{Descriptive analysis}

Figure 3 shows the preference mapping according to the PrefMap and PrefMFA for the DA. Subtle differences were observed in the positioning of the samples in the sensory spaces, although they were obtained by different multivariate methods. In the PrefMap, LS2, Bamboo, Commercial and Acacia samples were positioned in the region of greater acceptance $(60-70 \%$ of consumers liked these products), while LS1 
$(20-30 \%$ of consumers liked these products) and Eucalyptus $(30-40 \%$ of consumers liked these products) samples were positioned in the region of lower acceptance. In the PrefMFA, the samples placed in the areas of greater acceptance were commercial, bamboo and S2, and those placed in the less accepted region were Eucalyptus, Acacia and S1. Both methods showed optimal regions, where the preference would be greater in the red part of the sensory map, ie, in this place would be the ideal product. However, the PrefMFA showed a larger red area, even positioned in the barycenter of three real products. The small differences in the positioning of the samples in both sensory spaces are due to the fact that they share the same perceptual space. Considering that the experiment was carried out in individual sensory booths and that DA was performed by trained assessors who evaluated the sensory profile analytically, it can be stated that the liking of the bacon is based on its sensory properties. From this, Tuorila, (2007) argued that the sensory properties of foods and beverages are the basis of their acceptance and consumption.

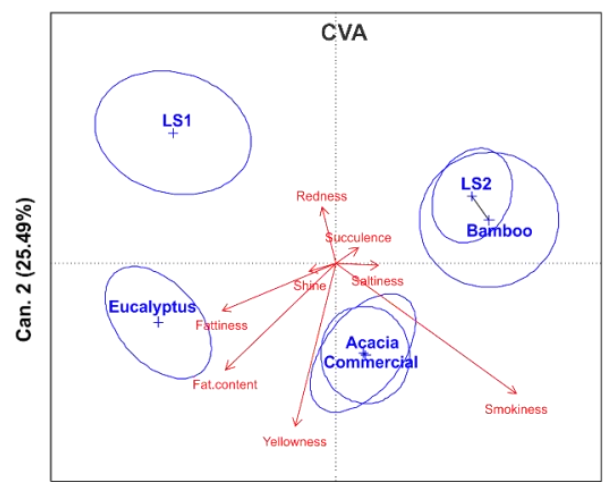

Can. $1(58.18 \%)$

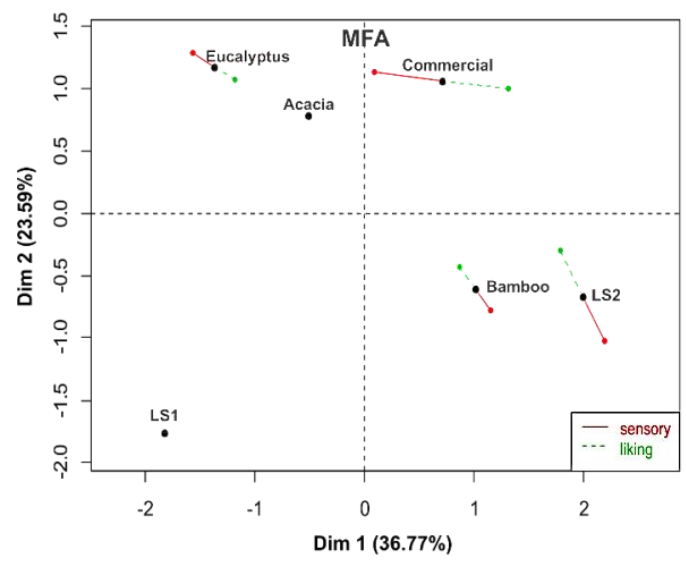

\subsubsection{Projective mapping}

Figure 4 shows the positioning of the samples considering the projective mapping as sensory technique. The positioning of the samples was different when the hedonic information was included in the MFA. This can be explained by the nature of the PM, which studies the sample representation. Representation from the social point of view is related to concepts, phrases, ideas, opinions, attitudes and values (Gómez-Corona et al., 2016).

When PrefMap was used, two clearly separated regions were observed: the red region composed of the most preferred samples (LS2, Bamboo, Commercial, Acacia) and the blue region composed of the least preferred samples (Eucalyptus and LS1). This arrangement of samples with high preferences was like that of the DA. It was also observed that no sample was close to the region of maximum preference. On the other hand, the PrefMFA also showed two clear regions of preference, where Eucalyptus, Acacia and LS1 had the lowest preference, while LS2, commercial and Bamboo had the highest preference.
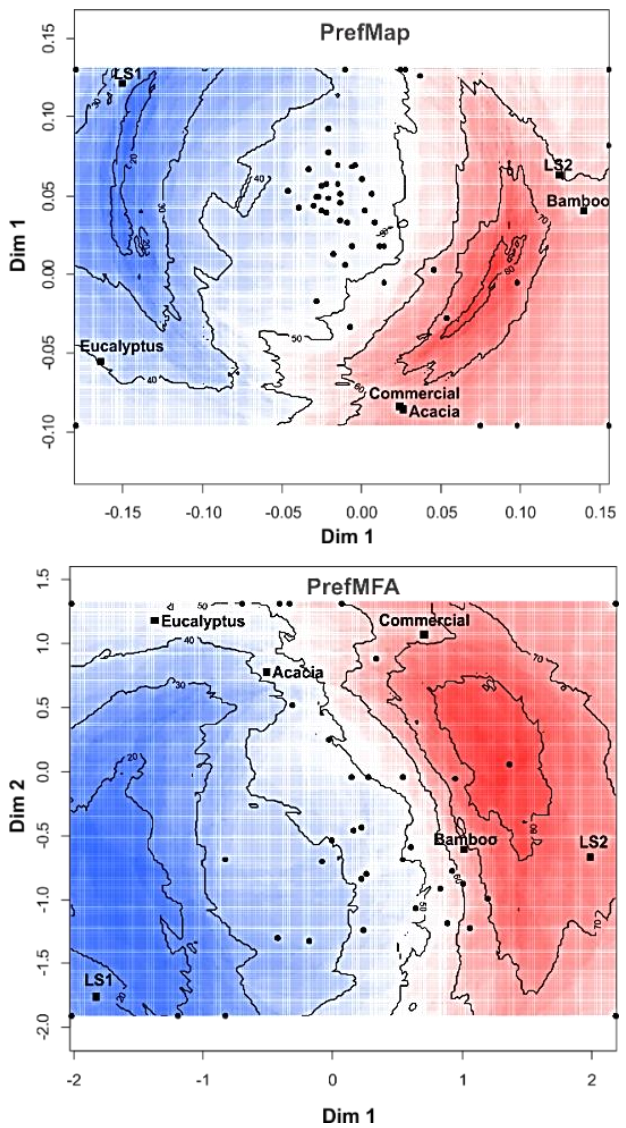

Figure 3. Positioning of the samples (left) and preference maps (right) for the descriptive analysis. 
It is necessary to emphasize that PrefMFA showed samples very close to the region of maximum preference, ie, close to the ideal product. This is probably due to the fact that this map contains perceptual information based on consumer coupled with consumer-based hedonic perception. Therefore, joining information provided only by consumers seems to improve the identification of the ideal bacon.

\subsubsection{CATA questions}

The positioning of the samples obtained by CA and MFA was similar for both multivariate procedures. As in the case of the DA, this is due to the fact that the sensory properties were the main drivers of liking. According to Figure 5, PrefMap and PrefMFA found similar preferred patterns, with commercial, bamboo and LS2 being the most preferred samples and Acacia, eucalyptus and LS2 the least preferred ones. In both multivariate methods the ideal product is close to bamboo, LS2 and the
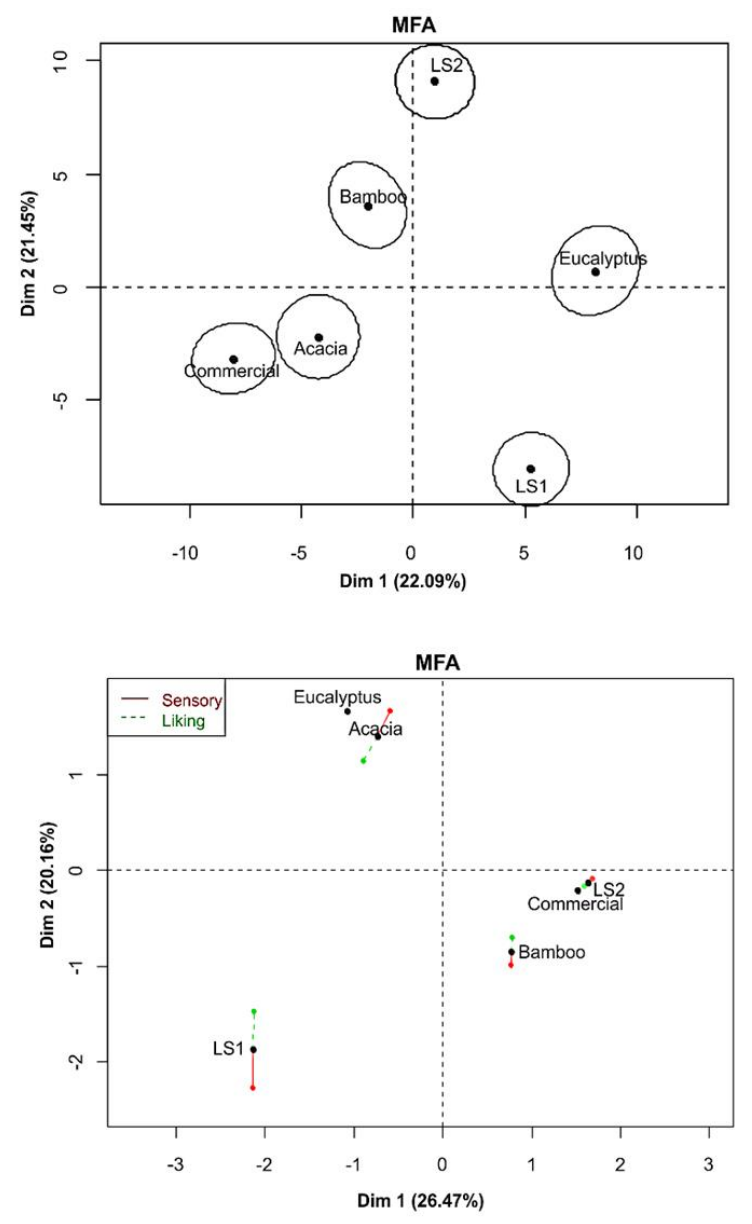

commercial bacons. The CATA method explicitly showed the ideal product coinciding with the position with the highest density preference in its respective preference map.

\subsection{Comparison of the sensory} methods and multivariate procedures

To compare the different sensory spaces in function of the sensory method and multivariate technique, the MFA using the coordinates of each sensory space was used. Figure 6 (which maintained $74.82 \%$ of the explained variance) shows, on the one hand, the position of each sensory method coupled to a given multivariate technique considering all samples (group representation) (Saldaña et al., 2015) and, on the other hand, the representation of each sample considering the different sensory techniques and statistical procedure used to obtain the sensory space (map of individual factors) (Pagès $y$ Husson, 2014).
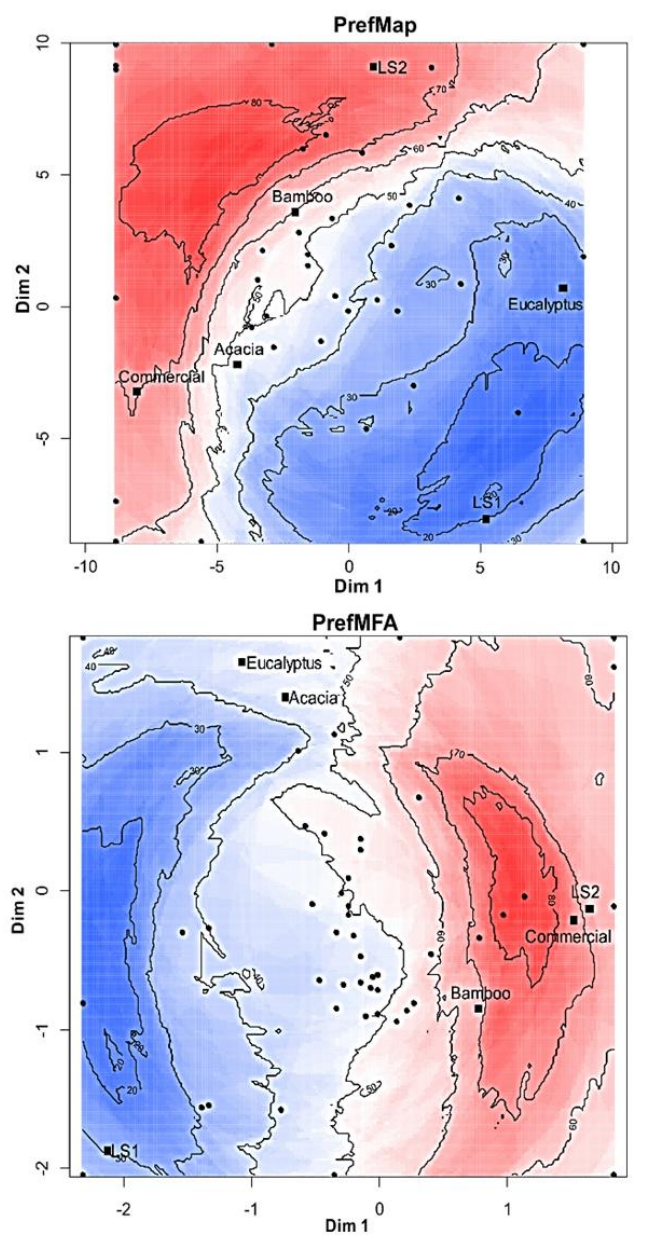

Figure 4. Positioning of the samples (left) and preference maps (right) for the projective mapping. 

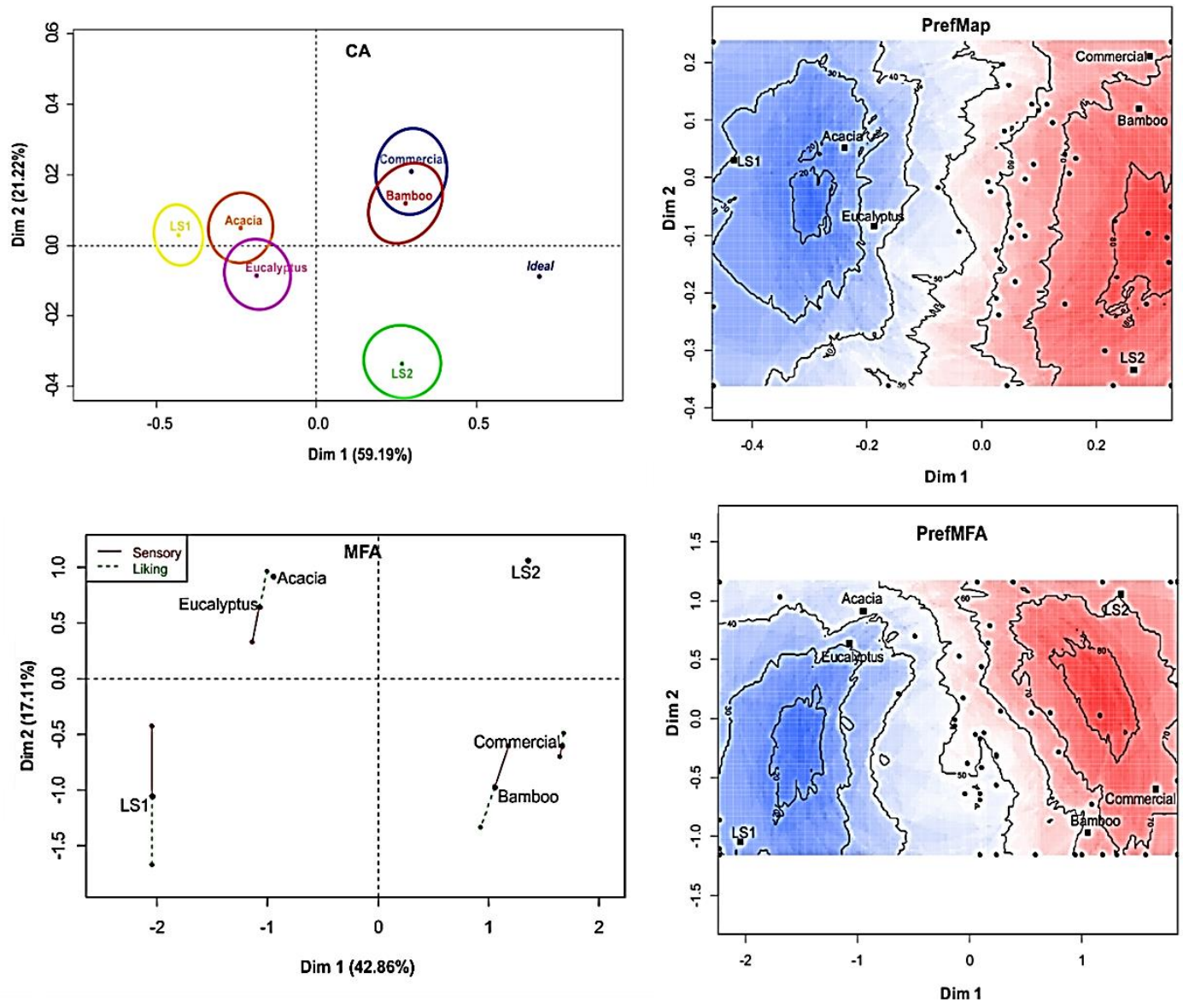

Figure 5. Positioning of the samples (left) and preference maps (right) for the CATA questions.

According to the "group representation", sensory space was the main cause of variations in the preference mapping, where the descriptive analysis performed by trained assessors was different from the consumer-based methods. This result was expected, since consumers and trained assessors use different cognitive strategies to evaluate the samples; while judges are analytical, consumers are holistic and intuitive. Similar results were found by Dooley et al. (2010), who reported that, despite the spatial similarity between the samples, the description of the ideal product was different. Sensory methods based on consumer response (PM and CATA) were similar. This is explained, as already mentioned, by the cognitive process used by consumers. This behavior was previously reported by other studies (Cadena et al., 2014; Hopfer y Heymann, 2013). Despite the small differences between multivariate techniques, they did not show a clear pattern of behavior for the consumer-based methods. For DA, the results were similar.

The "individual factor map" showed that the main differences between the sensory methods and the multivariate techniques for each sample are specifically in the second dimension. It is necessary to emphasize that for the most (LS2) and least (LS1) preferred products by consumers, there were no variations in the perceptual space. Therefore, if it is desired to find the ideal product from the position of the preferred products, little variation will be found between the sensory methods and multivariate techniques used to calculate the sensory space.

Overall, the ideal product is between the commercial product, LS2 and Bamboo. From this information, detailed explorations should be carried out based on the consumer's perception considering their individual differences, ie, identifying possible groups of consumers with their respective ideal products. 
Groups representation

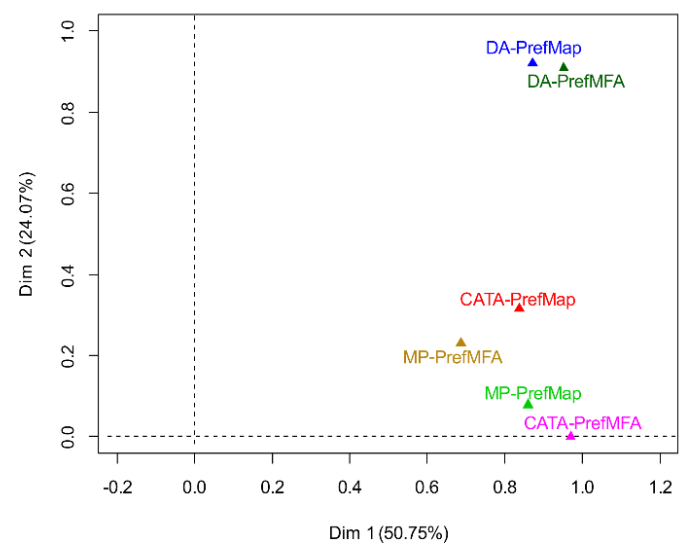

Individual factor map

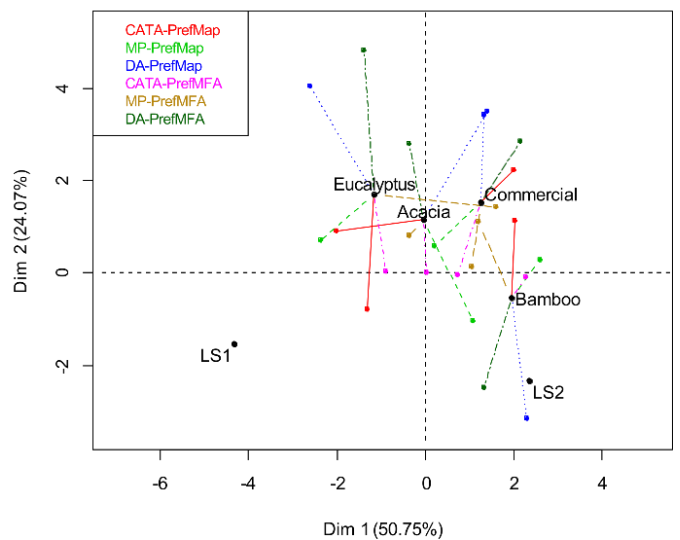

Figure 6. Multiple Factor analysis of the perceptual space of DA, PM, and CATA questions considering the PrefMap and PrefMFA procedures.

\section{Conclusions}

All preference maps showed two large regions, those of high and low preference. The most accepted bacon samples (according to the hedonic test) were always located in the high preference region. Our findings indicate that the sensory method had greater impact to obtain the sensory space than the multivariate technique. Therefore, the inclusion of hedonic scores in the calculation of the sensory space will not have a great effect on the identification of the ideal product. Subsequent studies with other food matrices are still necessary in order to generalize our results.

\section{Acknowledgments}

The authors are grateful to the São Paulo Research Foundation (FAPESP, Brazil), for funding the project No. 2016/15012-2. Erick Saldaña would like to thank the "Consejo Nacional de Ciencia, Tecnología e Innovación Tecnológica" (CONCYTEC, Peru) for the Ph.D Scholarship (Contract 104-2016-FONDECYT). Mariana Marinho Martins and Beatriz Schmidt Menegali acknowledges Coordination for the Improvement of Higher Education Personnel (CAPES) for the MSc scholarship.

\section{ORCID}

E. Saldaña ID https://orcid.org/0000-0002-4018-2852

B. Schidt iD https://orcid.org/0000-0002-1153-4564

M.M. Selani iD https://orcid.org/0000-0001-8184-742X

C.J. Contreras-Castillo iD https://orcid.org/0000-0002-0554-4694

\section{References}

AOAC. 1995. Official methods of analysis of AOAC International. Association of Official Analysis Chemists International.

Arditti, S. 1997. Preference mapping: A case study. Food Quality and Preference 8(5): 323-327.

Ares, G.; Giménez, A.; Gámbaro, A. 2006. Preference mapping of texture of dulce de leche. Journal of Sensory Studies 21(6): 553-571.
Ares, G.; Varela, P. 2017. Trained vs. consumer panels for analytical testing: Fueling a long lasting debate in the field. Food Quality and Preference 61: 79-86.

Ares, G.; Varela, P.; Rado, G.; Giménez, A. 2011. Identifying ideal products using three different consumer profiling methodologies. Comparison with external preference mapping. Food Quality and Preference 22(6): 581-591.

Cadena, R.S.; Caimi, D.; Jaunarena, I.; Lorenzo, I.; Vidal, L.; Ares, G., Deliza, R.; Giménez, A. 2014. Comparison of rapid sensory characterization methodologies for the development of functional yogurts. Food Research International 64: 446-455.

Cariou, V.; Verdun, S.; Qannari, E.M. 2014. Quadratic PLS regression applied to external preference mapping. Food Quality and Preference 32: 28-34.

Danzart, M.; Sieffermann, J.M.; Delarue, J. 2004. New developments in preference mapping techniques: finding out a consumer optimal product, its sensory profile and the key sensory attributes. In 7th Sensometrics Conference. Davis, CA. july, 2004.

Dooley, L.; Lee, Y.S.; Meullenet, J.F. 2010. The application of check-all-that-apply (CATA) consumer profiling to preference mapping of vanilla ice cream and its comparison to classical external preference mapping. Food Quality and Preference 21(4): 394-401.

El Ghaziri, A.; Qannari, E.M. 2015. Measures of association between two datasets; Application to sensory data. Food Quality and Preference 40(PA): 116-124.

Gómez-Corona, C.; Lelievre-Desmas, M.; Escalona Buendia, H.B.; Chollet, S.; Valentin, D. 2016. Craft beer representation amongst men in two different cultures. Food Quality and Preference 53: 19-28.

Hopfer, H.; Heymann, H. 2013. A summary of projective mapping observations - The effect of replicates and shape, and individual performance measurements. Food Quality and Preference 28: 164-181.

Huang, Y.; Li, H.; Huang, T.; Li, F.; Sun, J. 2014. Lipolysis and lipid oxidation during processing of Chinese traditional smoke-cured bacon. Food Chemistry 149: 31-39.

Kathrine, L.; Ellen, S.; Gunilla, L.; Margrethe, H.; Bjørg, E. 2013. Consumer acceptability of differently processed bacons using raw materials from entire males. LWT - Food Science and Technology 51(1): 205-210.

Lawless, H.T.; Heymann, H. 2010. Sensory evaluation of foods. Principles and practices. Sensory Evaluation of Foods. Principles and Practices. Second Edi. Springer. New York, E.E.U.U. 819 pp.

Lê, S.; Husson, F. 2008. Sensominer: A package for sensory data analysis. Journal of Sensory Studies, 23(1): 14-25. 
Lê, S.; Josse, J.; Husson, F. 2008. FactoMineR: A Package for Multivariate Analysis. Journal of Statistical Software 25(1): 1-18.

Lê, S.; Worch, T. 2014. When products are described by both liking and external information "independently." In Analyzing Sensory Data with R. Chapman and Hall/CRC. 271-299 pp.

Macfie, H. 2007. Preference mapping and food product development. In Consumer-led food product development. 551-592 pp.

Masson, M.; Saint-Eve, A.; Delarue, J.; Blumenthal, D. 2016. Identifying the ideal profile of French yogurts for different clusters of consumers. Journal of Dairy Science 99(5): 3421-3433.

Oltra, O.R.; Farmer, L.J.; Gordon, A.W.; Moss, B.W.; Birnie, J.; Devlin, D.J.; Tolland, E.L.; Tollerton, I.J.; Beattie, A.M.; Kennedy, J.T.; Farrell, D. 2015. Identification of sensory attributes, instrumental and chemical measurements important for consumer acceptability of grilled lamb Longissimus lumborum. Meat Science 100: 97-109.

Pagès, J.; Husson, F. 2014. Multiple factor analysis: Presentation of the method using sensory data. In Mathematical and Statistical Methods in Food Science and Technology: 87-102.

Parente, M.E.; Manzoni, A.V.; Ares, G. 2011. External Preference Mapping Of Commercial Antiaging Creams Based On Consumers' Responses To A Check-All-That-Apply Question. Journal of Sensory Studies 26(2): 158-166.

Peltier, C. 2015. Statistical analysis of sensory profiling data revisited by a database approach. Université de Bourgogne.

Peltier, C.; Visalli, M.; Schlich, P. 2015. Canonical Variate Analysis of Sensory Profiling Data. Journal of Sensory Studies 30(4): 316-328.

Resano, H.; Sanjuán, A.I.; Cilla, I.; Roncalés, P.; Albisu, L.M. 2010. Sensory attributes that drive consumer acceptability of dry-cured ham and convergence with trained sensory data. Meat Science 84(3): 344351

Robert, P.; Escoufier, Y. 1976. A Unifying Tool for Linear Multivariate Statistical Methods: The RV-Coefficient. Source Journal of the Royal Statistical Society. Series C (Applied Statistics) AppL. Statist 25(3): 257-265.

Saldaña, E.; Behrens, J.H.; Serrano, J.S.; Ribeiro, F.; de Almeida, M.A.; Contreras-Castillo, C.J. 2015. Microstructure, texture profile and descriptive analysis of texture for traditional and light mortadella. Food Structure 6: 13-20.

Saldaña, E.; Castillo, L.S.; Cabrera, J.; Siche, R., Behrens, J.H.; Selani, M.M.; de Almeida, M.A.; Duque, L.; Silva, J.; Contreras-Castillo, C.J. 2018. Relationship between volatile compounds and consumer-based sensory characteristics of bacon smoked with different Brazilian woods. Food Research International.

Saldaña, E.; Castillo, L.S.; Sánchez, J.C.; Siche, R.; de Almeida, M.A.; Behrens, J.H.; Selani, M.M.; Contreras-Castillo, C.J. 2018. Descriptive analysis of bacon smoked with Brazilian woods from reforestation: methodological aspects, statistical analysis, and study of sensory characteristics. Meat Science 140: 44-50.

Saldaña, E.; de Oliveira Garcia, A.; Selani, M.M.; Haguiwara, M.M.H.; de Almeida, M.A.; Siche, R.; Contreras-Castillo, C.J. 2018. A sensometric approach to the development of mortadella with healthier fats. Meat Science 137: 176-190.

Saldaña, E.; Lemos, C.; Selani, M.M.; Spada, F.P.; Almeida, M.A.; Contreras-castillo, C.J. 2015. Influence of animal fat substitution by vegetal fat on Mortadella- type products formulated with different hydrocolloids. Scientia Agricola 72(6): 495-503.

Saldaña, E.; Saldarriaga, L.; Cabrera, J.; Behrens, J.H.; Selani, M.M.; Rios-Mera, J.; Contreras-Castillo, C.J. 2019. Descriptive and hedonic sensory perception of Brazilian consumers for smoked bacon. Meat Science 147: 60-69.

Saldaña, E.; Saldarriaga, L.; Sanchez, J.C.; Siche, R.; Almeida, M.A.; Behrens, J.H.; Selani, M.M.; Contreras-Castillo, C.J. 2018. Descriptive analysis of bacon smoked with Brazilian woods from reforestation: methodological aspects, statistical analysis, and study of sensory characteristics. Meat Science 140: 44-50.

Schlich, P. 1995. Preference mapping: relating consumer preferences to sensory or instrumental measurements. Bioflavour'95. Retrieved from http://agris.fao.org/agrissearch/search/display.do?f=1996/FR/FR96042.xml;F R9604227

Soladoye, O.P.; Shand, P.; Dugan, M.E.R.; Gariépy, C.; Aalhus, J.L.; Estévez, M.; Juárez, M. 2017. Influence of cooking methods and storage time on lipid and protein oxidation and heterocyclic aromatic amines production in bacon. Food Research International 99: 660-669.

Tuorila, H. 2007. Sensory perception as a basis of food acceptance and consumption. In H. B. T.-C.-L. F. P. D. MacFie (Ed.), Consumer-Led Food Product Development. Woodhead Publishing. 34-65 pp.

Valentin, D.; Chollet, S.; Lelie, M. 2012. Quick and dirty but still pretty good: a review of new descriptive methods in food science. International Journal of Food Science and Technology 47: 1563-1578.

van Kleef, E.; van Trijp, H.C.M.; Luning, P. 2005. Consumer research in the early stages of new product development: a critical review of methods and techniques. Food Quality and Preference 16(3): 181-201.

van Kleef, E.; van Trijp, H.C.M.; Luning, P. 2006. Internal versus external preference analysis: An exploratory study on end-user evaluation. Food Quality and Preference 17(5): 387-399.

Vidal, L.; Tárrega, A.; Antúnez, L.; Ares, G.; Jaeger, S.R. 2015. Comparison of Correspondence Analysis based on Hellinger and chi-square distances to obtain sensory spaces from check-all-that-apply (CATA) questions. Food Quality and Preference 43: 106-112.

Worch, T. 2013. PrefMFA, a solution taking the best of both internal and external preference mapping techniques. Food Quality and Preference 30(2): 180-191. 